\title{
The parasitoid Praon volucre (Hymenoptera: Braconidae: Aphidiinae) as a potential biological control agent of the aphid Uroleucon ambrosiae (Hemiptera: Aphididae) on lettuce in Brazil
}

\author{
Bruno Freitas DE CONTI ${ }^{1}$, VAnda Helena Paes BUENO ${ }^{1}$ and Marcus Vinicius SAMPAiO ${ }^{2}$ \\ ${ }^{1}$ Universidade Federal de Lavras, Departamento de Entomologia, Caixa postal 3037, CEP 37200-000, Lavras-MG, Brazil; \\ e-mail: bfdeconti@yahoo.com.br; vhpbueno@ufla.br \\ ${ }^{2}$ Universidade Federal de Uberlândia, ICIAG, Campus Umuarama, Caixa postal 593, CEP 38400-902, Uberlândia-MG, Brazil; \\ e-mail: mvsampaio@iciag.ufu.br
} Key words. Biological control, host quality, host size, development, aphid, Uroleucon ambrosiae, Macrosiphum euphorbiae,
parasitoid, Praon volucre, Lactuca sativa

\begin{abstract}
The aphid Uroleucon ambrosiae (Thomas) is one of the principal pests found on greenhouse lettuce crops, and there is no efficient biological control agent of this pest in Brazil. This work evaluates the aphid U. ambrosiae as a host for the parasitoid Praon volucre (Haliday), aimed at using $P$. volucre as a potential biological control agent of $U$. ambrosiae on lettuce. As Macrosiphum euphorbiae (Thomas) is a common host of $P$. volucre in the field, the development of the parasitoid was compared on these two aphid species. Twenty nymphs of the $2^{\text {nd }}$ instar were kept with $P$. volucre for one hour at $22 \pm 1{ }^{\circ} \mathrm{C}, 70 \pm 10 \% \mathrm{RH}$ and a $12 \mathrm{~h}$ photophase. The size of the aphid's tibiae at the moment of oviposition indicated that there was no significant size difference between $U$. ambrosiae $(0.6 \pm 0.02 \mathrm{~mm})$ and $M$. euphorbiae $(0.7 \pm 0.03 \mathrm{~mm})$. When mummies were formed, M. euphorbiae had significantly longer tibia $(1.5 \pm 0.03 \mathrm{~mm})$ than $U$. ambrosiae $(1.4 \pm 0.02 \mathrm{~mm})$. No significant differences were detected in the percentage emergence $(74.9 \pm 7.92$ and $87.5 \% \pm 3.31$ for $U$. ambrosiae and M. euphorbiae, respectively), or proportion of female offspring (56.2 \pm 7.62 and $44.2 \pm 7.14 \%$ ). The development time from oviposition to adult and longevity of females and males of $P$. volucre reared on the two host species were not different. High parasitism levels were recorded for both host aphid species, but the percentage parasitism of M. euphorbiae $(54.4 \pm 4.40)$ was higher than of $U$. ambrosiae $(35.6 \pm 5.30)$. Female parasitoids reared on M. euphorbiae had longer tibiae $(0.78 \pm 0.01 \mathrm{~mm})$ than those reared on $U$. ambrosiae $(0.72 \pm 0.01 \mathrm{~mm})$. Our results demonstrate that the alternative host species U. ambrosiae, compared to the natural host species M. euphorbiae, affects the female's size, but did not affect parasitoid development time, longevity, emergence or sex ratio. The parasitoid $P$. volucre seems to be a good candidate for using as a biological control agent of $U$. ambrosiae on lettuce in Brazil.
\end{abstract}

\section{INTRODUCTION}

The aphids Macrosiphum euphorbiae (Thomas) and Uroleucon ambrosiae (Thomas) are two of the major pests that regularly attack greenhouse lettuce crops (Auad et al., 2002). U. ambrosiae is an aphid from the Nearctic region, which colonizes a range of Compositae plants in South America (Carvalho et al., 1998), and has increased its status as a pest with the increase in the hydroponic production of lettuce in Brazil (Starý et al., 2007). The koinobiont endoparasitoid Praon volucre (Haliday), of Palearctic origin, was introduced into Brazil for the biological control of the wheat aphids Metopolophium dirhodum (Walker) and Sitobion avenae (Fabricius) (Gassen $\&$ Tambasco, 1983) and parasitizes several Macrosiphini in the field, including M. euphorbiae and Uroleucon sp. (Starý et al., 2007). According to Starý et al. (2007) the native Aphidiinae fauna of Uroleucon in South America is not well known and although they recorded large colonies of $U$. ambrosiae on lettuce plants without parasitoids they did not reconmend the introduction of exotic parasitoids species to control $U$. ambrosiae before acquiring a better knowledge of the indigenous parasitoids of the local fauna. $P$. volucre is not a native species but has become established and makes up part of the parasitoid guild attacking Uroleucon species and might be a good candidate for use as a biological control agent against lettuce aphids in Brazil.

The aim of this work was to determine whether $P$. volucre is as a potential biological control agent of $U$. ambrosiae, with the objective of controlling this aphid without introducing an exotic aphid parasitoid. As $M$. euphorbiae is a common host of $P$. volucre in the field, the development of the parasitoid was compared on these two aphid species.

\section{MATERIAL AND METHODS}

\section{Insect rearing}

The aphids M. euphorbiae and U. ambrosiae were evaluated as hosts for $P$. volucre. The insects were collected at the Federal University of Lavras, Brazil. Aphids were collected from a hydroponic lettuce crop and reared in climatic chambers at $22 \pm$ $1{ }^{\circ} \mathrm{C}, 70 \pm 10 \% \mathrm{RH}$ and a $12 \mathrm{~h}$ photophase. Pieces of lettuce leaf (Lactuca sativa L.) were placed in $15 \mathrm{~cm}$ Petri dishes on a layer of $1 \%$ agar/water. Parasitoids were collected from Rhodobium porosum (Sanderson) and M. euphorbiae mummies on rose bushes. Parasitoid rearing was carried out on M. euphorbiae maintained in $15 \mathrm{~cm}$ Petri dishes in climatic chamber at $22 \pm$ $1{ }^{\circ} \mathrm{C}, 70 \pm 10 \% \mathrm{RH}$ and a $12 \mathrm{~h}$ photophase. A male and female parasitoids were kept in $10 \times 8 \mathrm{~mm}$ glass tubes and the females 
used in the experiments came from tubes where mating was observed.

\section{Assessing $\boldsymbol{U}$. ambrosiae as host for $\boldsymbol{P}$. volucre}

The experiments to test $M$. euphorbiae and $U$. ambrosiae as hosts for $P$. volucre were carried out in climatic chambers at 22 $\pm 1{ }^{\circ} \mathrm{C}, 70 \pm 10 \% \mathrm{RH}$ and a $12 \mathrm{~h}$ photophase. Approximately 50 adults of each aphid species were maintained for $24 \mathrm{~h}$ in $15 \mathrm{~cm}$ Petri dishes on pieces of lettuce leaf on $1 \%$ solution agar/water kept in climatic chambers at $25 \pm 1{ }^{\circ} \mathrm{C}, 70 \pm 10 \% \mathrm{RH}$ and a $12 \mathrm{~h}$ photophase. After this period, the adult aphids were removed and 2 nd instar apterous nymphs ( $24 \mathrm{~h}$ old) were used in the experiments. The presence and number of exuviae were used as an indication that the nymphs were in the 2 nd instar. In order to minimize the chance of $3 \mathrm{rd}$ instar nymphs being presented in the experiments, 2nd instar sized aphid nymphs of each aphid species were chosen and presented to each parasitoid.

A single 24-48-h old mated $P$. volucre female, with no previous oviposition experience, was released in a $5 \mathrm{~cm}$ Petri dish containing 202 nd instar nymphs of one of the aphid species on a piece of lettuce leaf on $1 \%$ solution agar/water. The parasitoid female was removed after one hour and the aphids were maintained under the same climatic conditions. Fifteen parasitoid females were evaluated for each host species. Five days after the parasitoid was removed the aphids were transferred to new $5 \mathrm{~cm}$ Petri dishes with fresh pieces of lettuce leaf until mummies formed. The experiment was checked daily to evaluate the developmental time and adult longevity of the parasitoid. A mummy was considered to be completely formed, once the parasitoid larva had formed the cocoon below the aphid skin. The individual mummies were placed in $10 \mathrm{~cm} \times 8 \mathrm{~mm}$ glass vials until adult emergence, when the parasitoids were supplied daily with water and honey drops placed on the walls of the vials.

\section{Host and parasitoid size}

Aphids from the same dishes of nymphs used in the experiments were used to measure host size at oviposition (initial host size). The right hind tibia was removed from each aphid and placed in a drop of $70 \%$ alcohol on a slide covered with a cover slip and then measured under an optical microscope with graded ocular at a $100 \times$ magnification. Females of twenty nymphs of each aphid species were measured.

Tibiae of both males and females of the parasitoids reared on each aphid species were measured using the same method. Hind tibial lengths of mummies were also measured (host final size). Forty $P$. volucre adults were measured for each host species, 20 males, 20 females, and their respective mummies.

\section{Data analysis}

The sex ratio (percentage of female), parasitism and emergence percentages, as well as the developmental time and longevity of the parasitoids reared on each aphid species were
TABLE 1. Hind tibial length of the hosts $U$. ambrosiae and $M$. euphorbiae at oviposition (initial) and mummy formation (final), parasitism and emergence percentages, and percentage of females of $P$. volucre that developed in these aphids. $22 \pm$ $1{ }^{\circ} \mathrm{C}, 70 \pm 10 \% \mathrm{RH}$ and a $12 \mathrm{~h}$ photophase. Averages ( \pm standard error) for each aphid species followed by the same letter on the same line indicate that they do not differ $\mathrm{F}$ test and a $5 \%$ probability.

\begin{tabular}{lrr}
\hline \multirow{2}{*}{ Parameters } & \multicolumn{2}{c}{ Host (n) } \\
\cline { 2 - 3 } & \multicolumn{1}{c}{ U. ambrosiae } & \multicolumn{1}{c}{ M. euphorbiae } \\
\hline Host tibia initial size & $0.6 \pm 0.02 \mathrm{a}(20)$ & $0.7 \pm 0.03 \mathrm{a} \mathrm{(20)}$ \\
Host tibia final size & $1.4 \pm 0.02 \mathrm{~b}(20)$ & $1.5 \pm 0.03 \mathrm{a}(20)$ \\
Percentage parasitism & $35.6 \pm 5.30 \mathrm{~b}(15)$ & $54.4 \pm 4.40 \mathrm{a}(15)$ \\
Percentage emergence & $74.9 \pm 7.92 \mathrm{a}(15)$ & $87.5 \pm 3.31 \mathrm{a}(15)$ \\
Females (\%) & $56.2 \pm 7.62 \mathrm{a}(15)$ & $44.2 \pm 7.14 \mathrm{a}(15)$ \\
\hline
\end{tabular}

recorded. Parasitoid size as well as initial and final host size were also compared. For calculating percentages data obtained for each $P$. volucre female $(\mathrm{n}=15)$ was pooled. When mating is observed sperm may have not passed into the female parasitoid, and only male offspring are produced; to avoid this, the analyses included only the results for Petri dishes where at least one female occurred among the offspring. The production of daughters is the simplest way of confirming that a female parasitoid was mated. For developmental time the results for the parasitoids that emerged were used and for longevity 60 adults were evaluated for each host species, 30 females and 30 males. An analysis of variance was performed and the averages compared using a $\mathrm{F}$ test with a $5 \%$ level of significance.

\section{RESULTS}

No significant differences were found in the hind tibial lengths of the second instar host aphids indicating that the initial size of the aphids was similar. However, the final host size in the case of $M$. euphorbiae was larger than that in $U$. ambrosiae (Table 1). The percentage of parasitism of $U$. ambrosiae was lower than of $M$. euphorbiae, indicating a higher successful parasitism by $P$. volucre of the natural host species (Table 1). The percentage emergence and sex ratio (percentage of female offspring) of $P$. volucre did not differ in parasitized $U$. ambrosiae and $M$. euphorbiae (Table 1). The developmental time, from oviposition to mummy formation, for female parasitoids was shorter when they parasitized $M$. euphorbiae than $U$. ambrosiae. However, the developmental times, from oviposition to mummy formation, for males, and oviposition to adult for both parasitoid sexes was the same for both

TABLE 2. Developmental time (from oviposition to mummy formation and from oviposition to adult), longevity, and hind tibial length of the females and males of the parasitoid $P$. volucre at $22 \pm 1{ }^{\circ} \mathrm{C}, 70 \pm 10 \% \mathrm{RH}$ and a $12 \mathrm{~h}$ photophase. Averages $( \pm$ standard error) of each aphid species followed by the same letter on the same line indicate that for each sex they do not differ, $\mathrm{F}$ test and a $5 \%$ probability. (UA = Uroleucon ambrosiae; $\mathrm{ME}=$ Macrosiphum euphorbiae).

\begin{tabular}{|c|c|c|c|c|}
\hline \multirow{2}{*}{ P. volucre biological parameters } & \multicolumn{2}{|c|}{ Female (n) } & \multicolumn{2}{|c|}{ Male (n) } \\
\hline & UA & $\mathrm{ME}$ & UA & ME \\
\hline Oviposition-mummy (days) & $7.0 \pm 1.43$ a (38) & $7.9 \pm 1.65 \mathrm{~b}(45)$ & $7.7 \pm 0.94 \mathrm{a}(34)$ & $7.0 \pm 1.30 \mathrm{a}(69)$ \\
\hline Oviposition-adult (days) & $15.9 \pm 1.51 \mathrm{a}(38)$ & $15.3 \pm 2.32 \mathrm{a}(45)$ & $15.8 \pm 2.25 \mathrm{a}(34)$ & $15.2 \pm 1.90 \mathrm{a}(69)$ \\
\hline Longevity (days) & $18.4 \pm 5.49 \mathrm{a}(30)$ & $20.3 \pm 6.23$ a $(30)$ & $17.8 \pm 5.00 \mathrm{a}(30)$ & $19.5 \pm 4.18$ a (30) \\
\hline Parasitoid tibial length (mm) & $0.72 \pm 0.01 \mathrm{a}(20)$ & $0.78 \pm 0.01 \mathrm{~b}(20)$ & $0.62 \pm 0.01 \mathrm{a}(20)$ & $0.66 \pm 0.01 \mathrm{a}(20)$ \\
\hline
\end{tabular}


aphid species (Table 2). There were no differences in the longevity of males or females of $P$. volucre when they developed in the different hosts (Table 2). The females of $P$. volucre reared on $M$. euphorbiae were larger than when reared on $U$. ambrosiae. However, there was no difference in the hind tibia size of males of $P$. volucre reared on the two hosts (Table 2).

\section{DISCUSSION}

The percentage of parasitism recorded in this study was a combination of host acceptance and host suitability (Vinson \& Iwantsch, 1980). Therefore, it is unknown whether the lower percentage of parasitism of $U$. ambrosiae was due to its lower host acceptance or mortality during the parasitoid's immature stages. However, percentage parasitism and emergence were high, indicating that $P$. volucre readily parasitized this host and that it was suitable for the parasitoid's development. In the field, $P$. volucre parasitizes both the invasive and indigenous species of Uroleucon in Brazil, but not U. ambrosiae (Starý et al., 2007). The lack of parasitism of $U$. ambrosiae in the field does not appear to be due to incompatibility of the parasitoid with the host.

The developmental time of $P$. volucre on the two host species did not indicate a difference in host quality for the parasitoid. This period was longer when developing in $U$. ambrosiae than $M$. euphorbiae only for the period from oviposition to mummy formation of female parasitoids. Mescheloff \& Rosen (1988) found a similar egg-mummy developmental time (7 days), and shorter egg to adult period (12 days) when $P$. volucre developed in $U$. sonchi and $M$. rosae at $22^{\circ} \mathrm{C}$. The same was observed by Sigsgaard (2000), with 7.8 and 10.1 days for these periods for $P$. volucre developing in $S$. avenae at $20^{\circ} \mathrm{C}$.

We used hind tibial length as an index of aphid and parasitoid body mass. Even though hind tibial length gives only an approximate measure of mass it is a very practical method (Nicol \& Mackauer, 1999). The larger size of the female $P$. volucre that developed in $M$. euphorbiae is related to the host size. Although host sizes were similar at oviposition the size at mummification was large for $M$. euphorbiae than $U$. ambrosiae. Large hosts are normally a better quality host and result in the development of larger parasitoids that have a competitive advantage over those developing in smaller conspecifics (Cloutier et al., 2000; Chau \& Mackauer, 2001; Ellers et al., 2001). Further studies are needed to determine if the large size of female $P$. volucre when reared on $M$. euphorbiae is associated with an increase in fitness.
The parasitoid $P$. volucre accepted and developed well on $U$. ambrosiae. Although parasitizing the alternative host species, $U$. ambrosiae, compared to the natural host species, M. euphorbiae, resulted in a smaller female parasitoid it did not affect parasitoid developmental time, longevity, percentage emergence, or sex ratio. As both aphid species are lettuce pests, the parasitoid $P$. volucre might be a good candidate for testing as a biological control agent of $M$. euphorbiae and $U$. ambrosiae in greenhouse using hydroponic production systems for growing lettuce in Brazil. Therefore, new introductions of aphid parasitoids may not be necessary for the biological control of $U$. ambrosiae in Brazil.

\section{REFERENCES}

Auad A.M., Freitas S. \& Barbosa L.R. 2002: Ocorrência de afídeos em alface (Lactuca sativa L.) em cultivo hidropônico. Neotrop. Entomol. 31: 335-339.

Cloutier C., Duperron J., Tertuliano M. \& Mcneil J.N. 2000: Host instar, body size and fitness in the koinobiontic parasitoid Aphidius nigripes. Entomol. Exp. Appl. 97: 29-40.

Carvalho R.C.Z, Blackman R.L. \& Spence J.M. 1998: The genus Uroleucon Mordvilko (Insecta, Aphidoidea) in South America, with a key and descriptions of four new species. Zool. J. Linn. Soc. 123: 117-141.

Chau A. \& Mackauer M. 2001: Preference of the aphid parasitoid Monoctomus paulensis (Hymenoptera: Braconidae, Aphidiinae) for different aphid species: female choice and offspring survival. Biol. Control 20: 30-38.

Ellers J., Bax M. \& Van Alphen J.J.M. 2001: Seasonal changes in female size and its relation to reproduction in the parasitoid Asobara tabida. Oikos 92: 309-314.

Gassen D.N. \& Tambasco F.J. 1983: Controle biológico dos pulgões do trigo no Brasil. Informe Agropec. 9: 49-51.

Mescheloff E. \& Rosen D. 1988: Biosystematic studies on the Aphidiidae of Israel (Hymenoptera: Ichneumonoidea) 2. The Genera Ephedrus and Praon. Israel J. Entomol. 22: 75-100.

Nicol C.M.Y. \& Mackauer M. 1999: The scaling of body size and mass in a host-parasitoid association: influence of host species and stage. Entomol. Exp. Appl. 90: 83-92.

SigsGaARD L. 2000: The temperature-dependent duration of development and parasitism of three cereal aphid parasitoids, Aphidius ervi, A. rhopalosiphi, and Praon volucre. Entomol. Exp. Appl. 95: 173-184.

Starý P., Sampaio M.V. \& Bueno V.H.P. 2007: Aphid parasitoids (Hymenoptera, Braconidae, Aphidiinae) and their associations related to biological control in Brazil. Rev. Bras. Entomol. 51: 107-118.

Vinson S.B. \& IwANTSCH G.F. 1980: Host suitability for insect parasitoids. Annu. Rev. Entomol. 25: 397-419.

Received September 18, 2007; revised and accepted March 13, 2008 